RESPECTFULLY DEDICATED, BY PERMISSION, TO MR.GLENN H. CURTISS, THE FAMOUS AVIATOR.
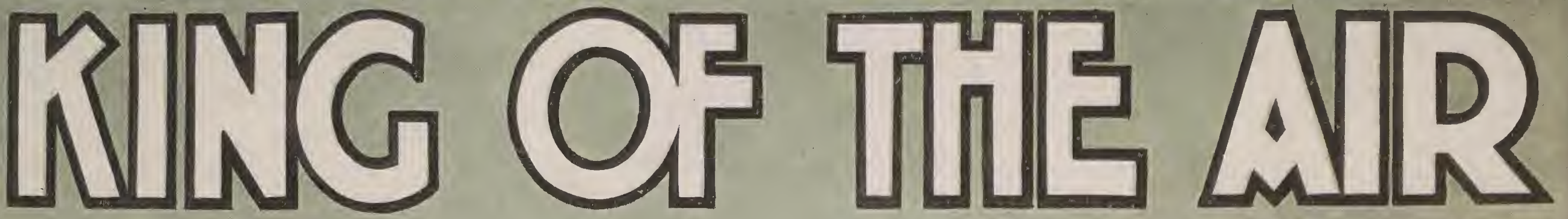

MARCH ANDTWOSTEP

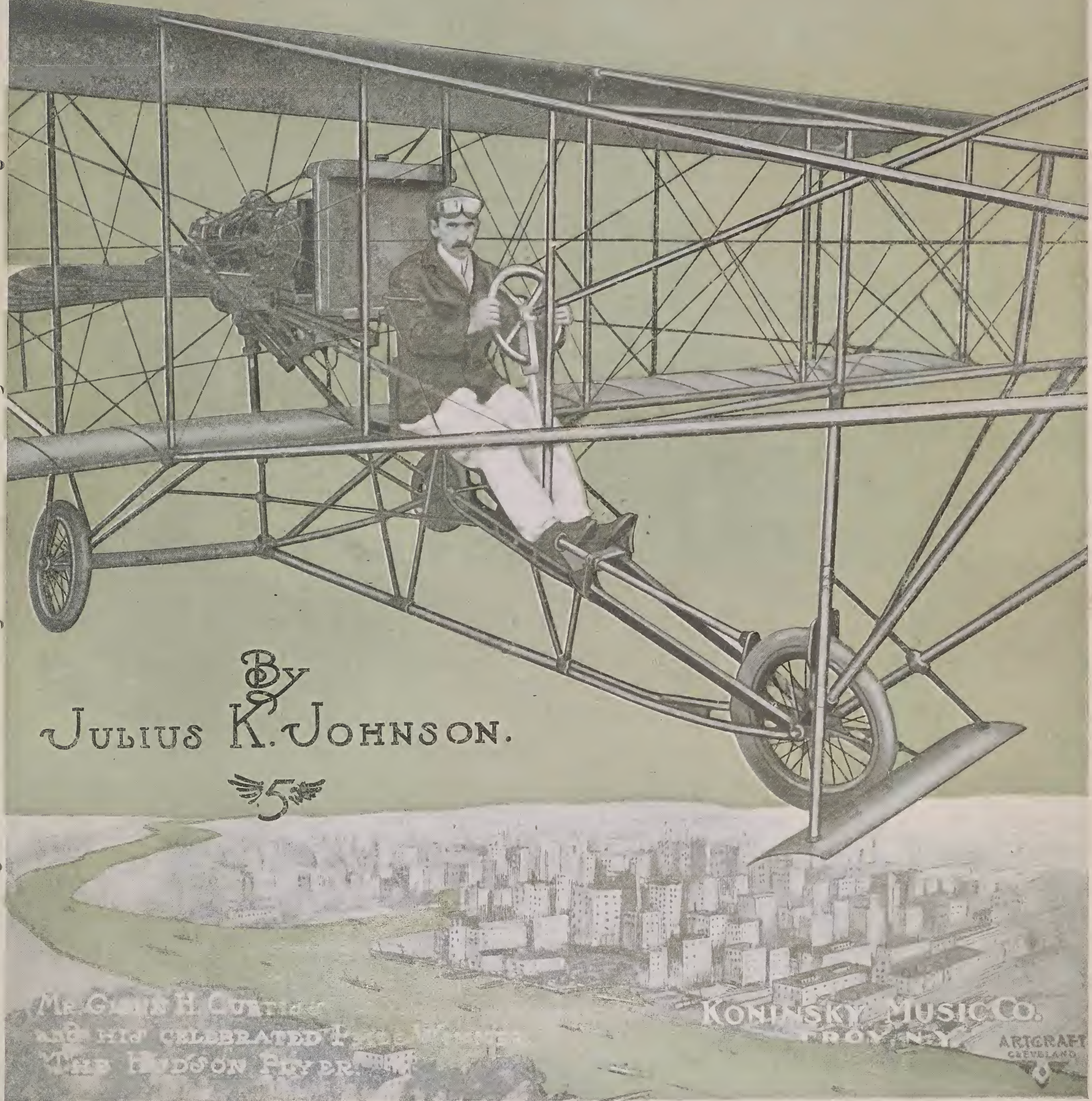




\title{
"KING OF THE AIR"
}

\author{
MARCH and Two-SteP.
}

JULIUS K. JOHNSON.
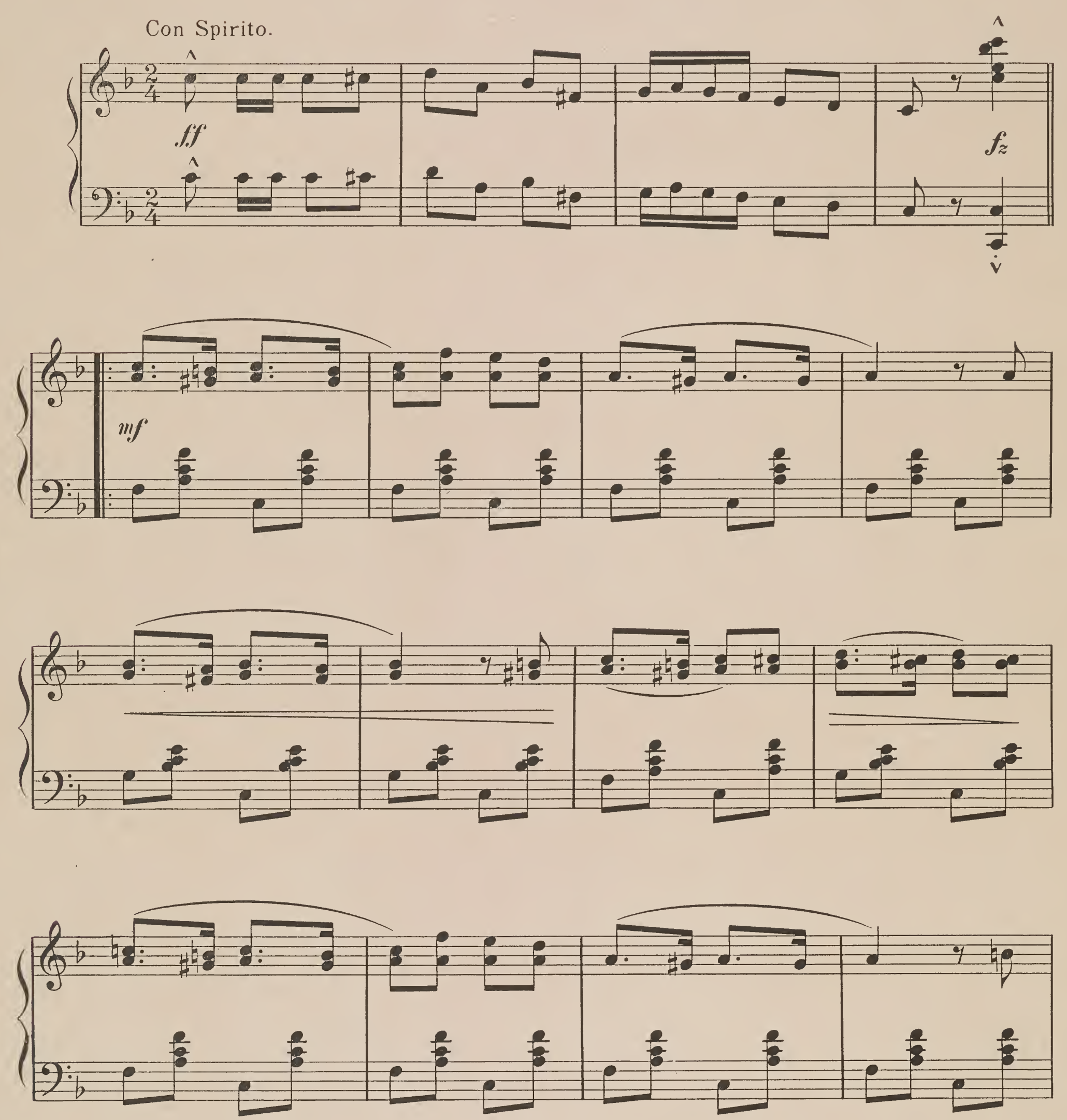

Copyright MCMX by Koninsky Music Co.

All Rights Reserved. 

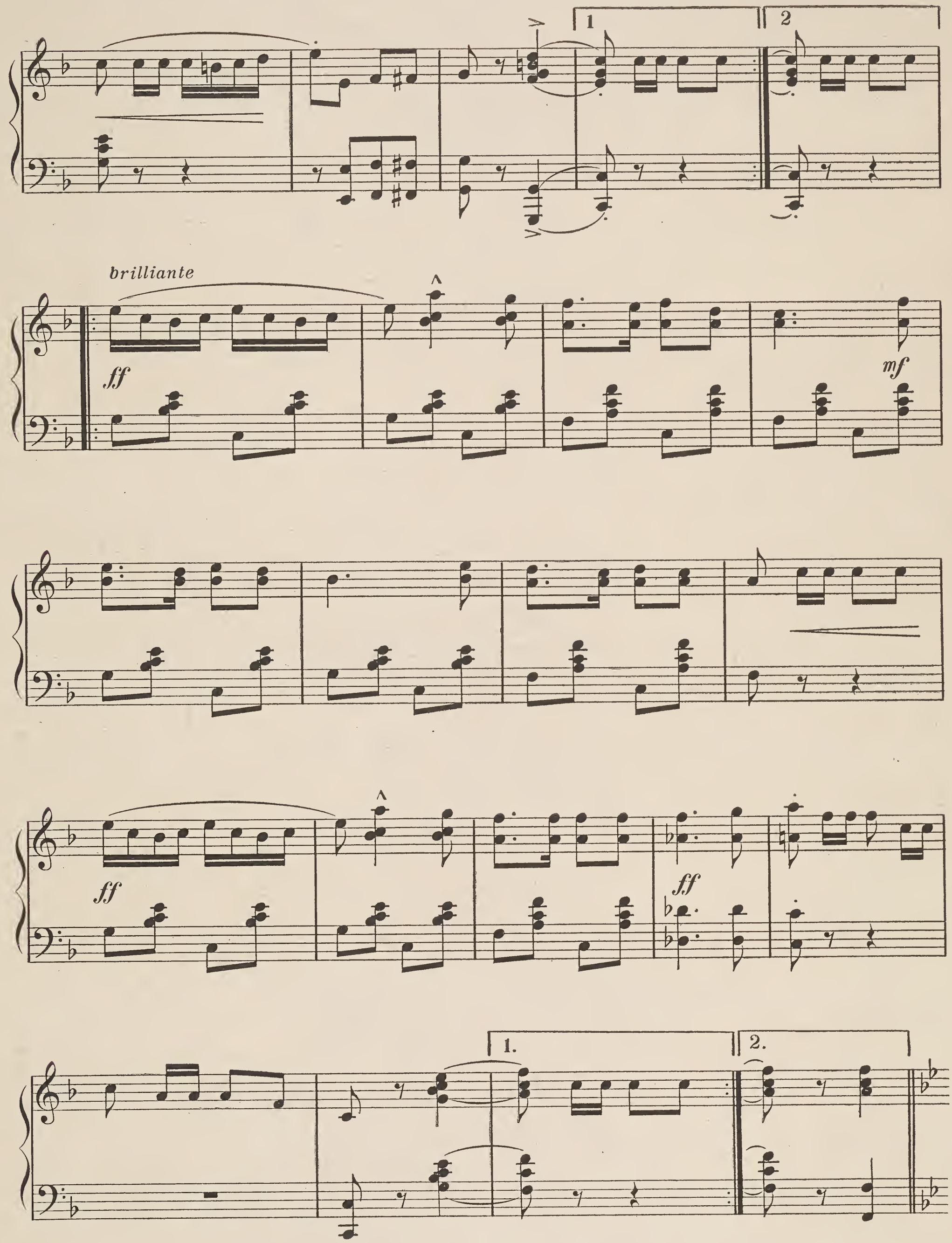

King of the Air - 4 


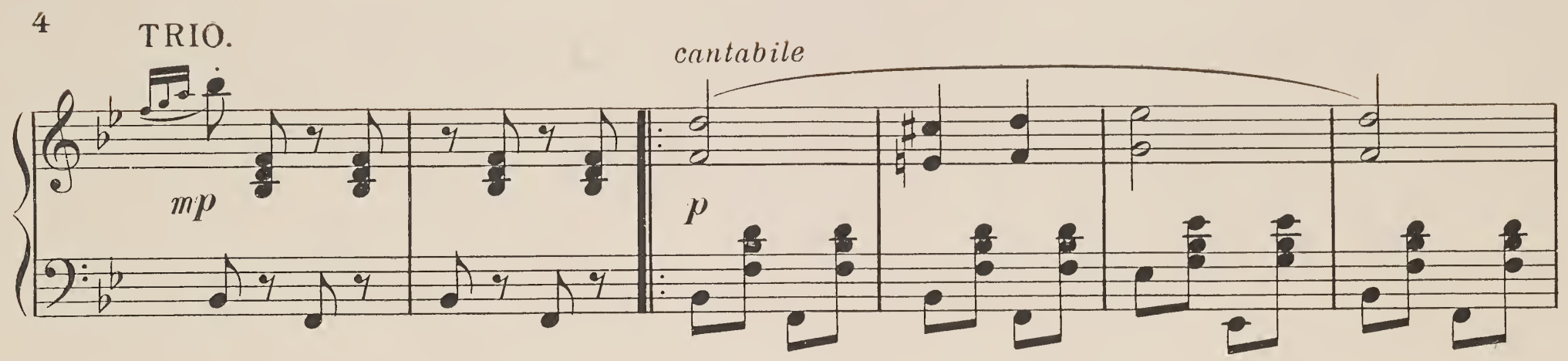

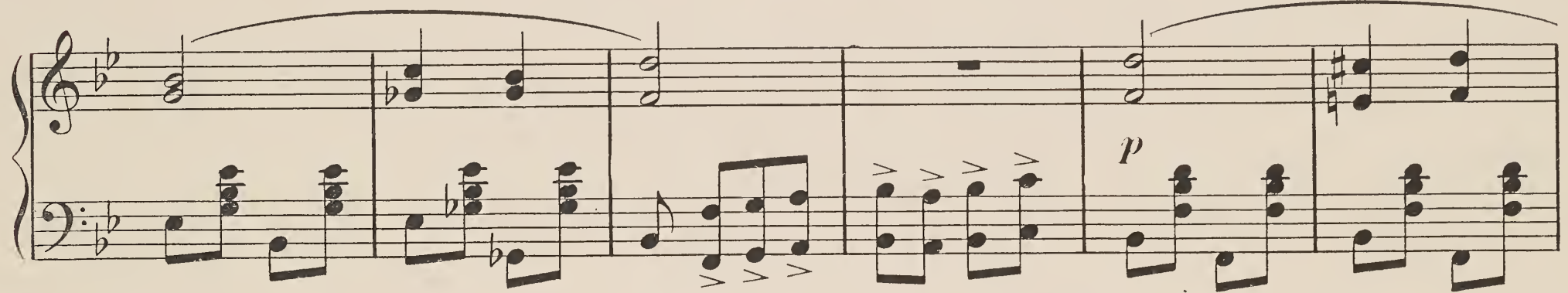

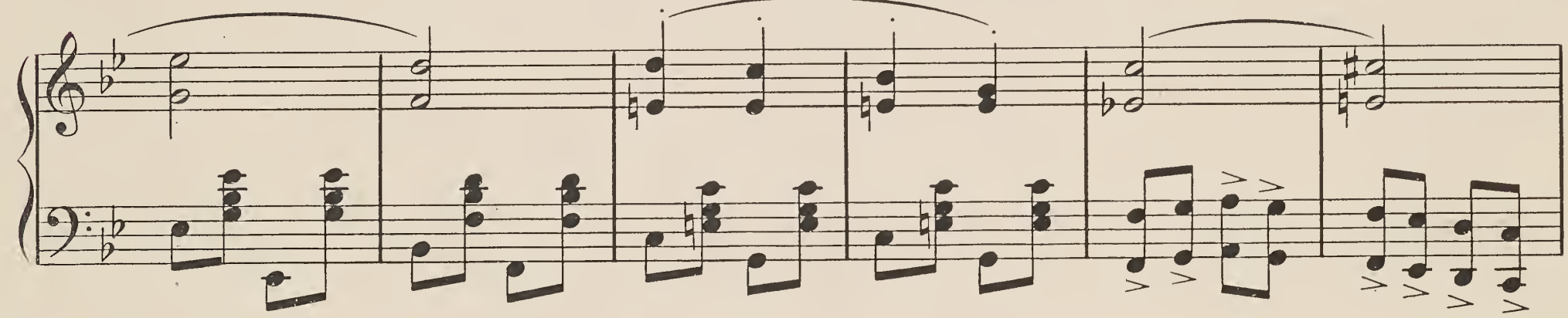

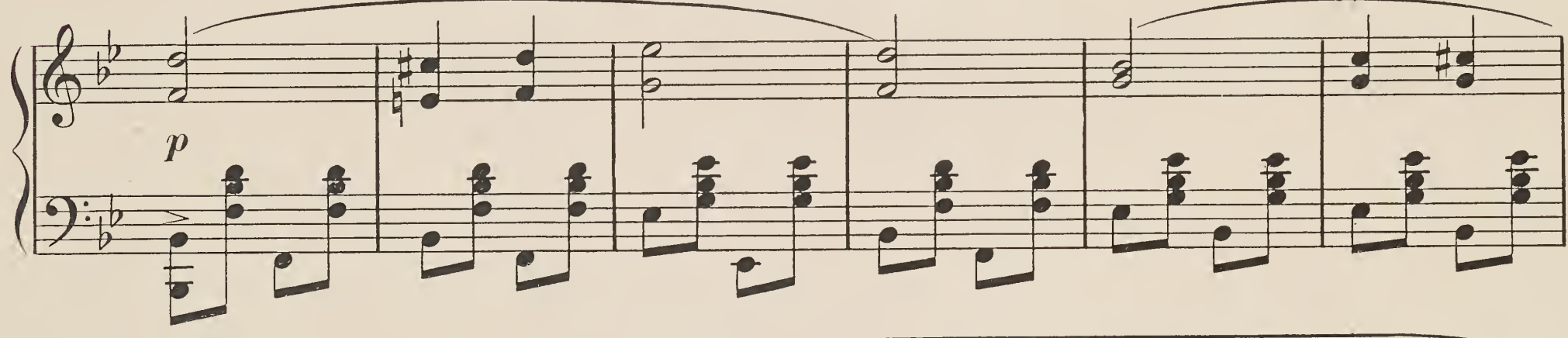

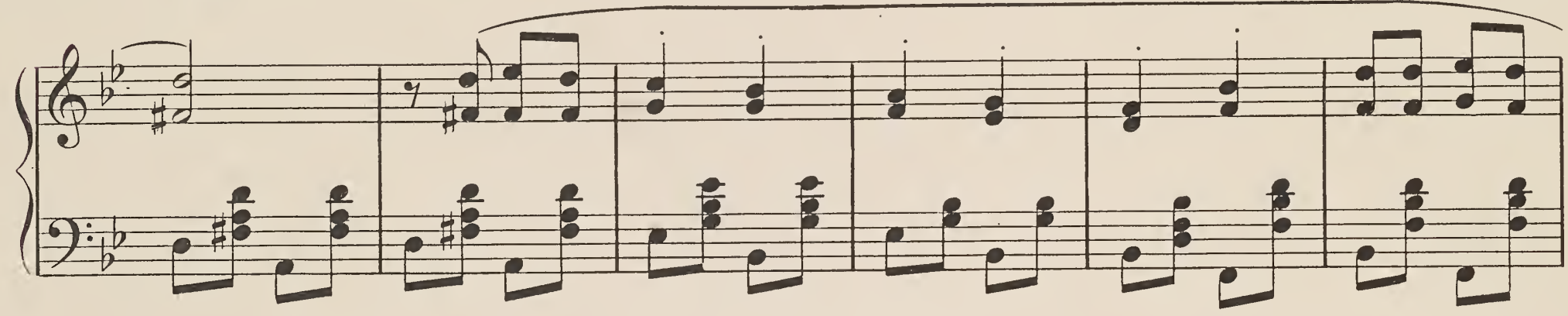

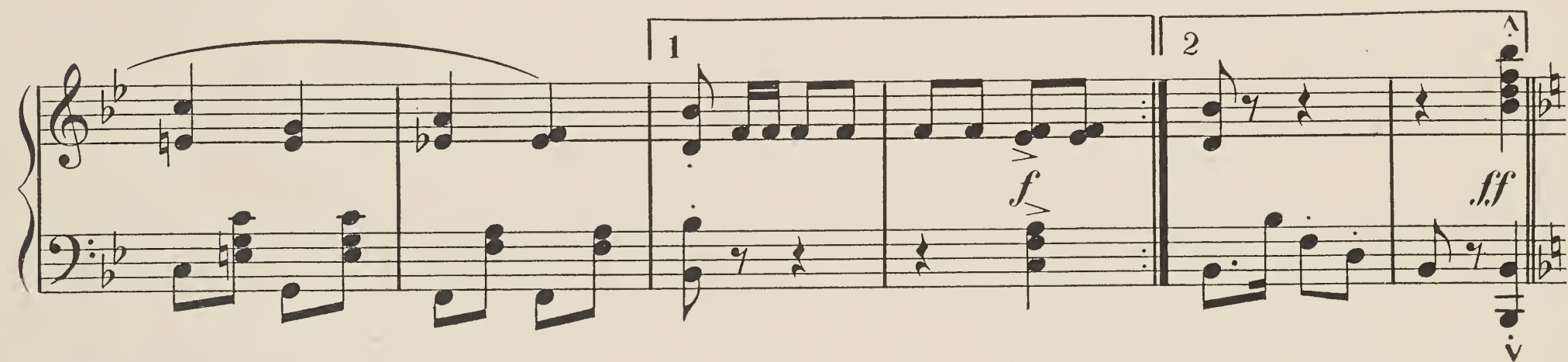

King of the Air - 4 

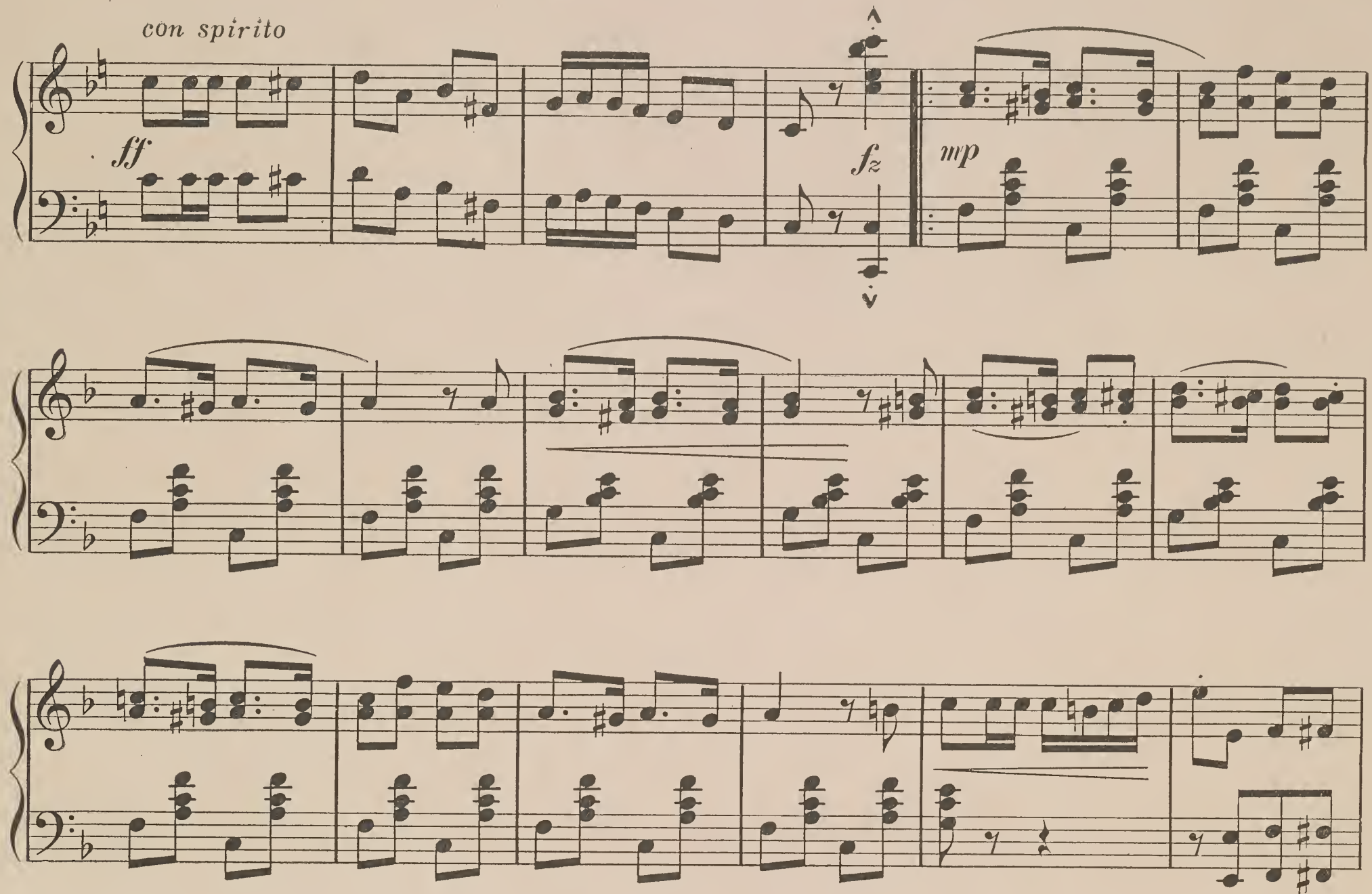

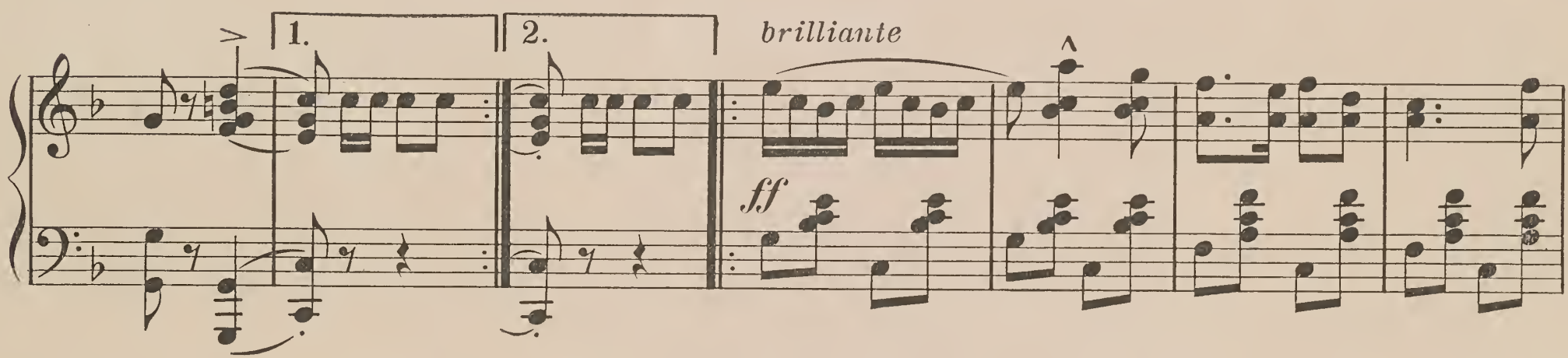

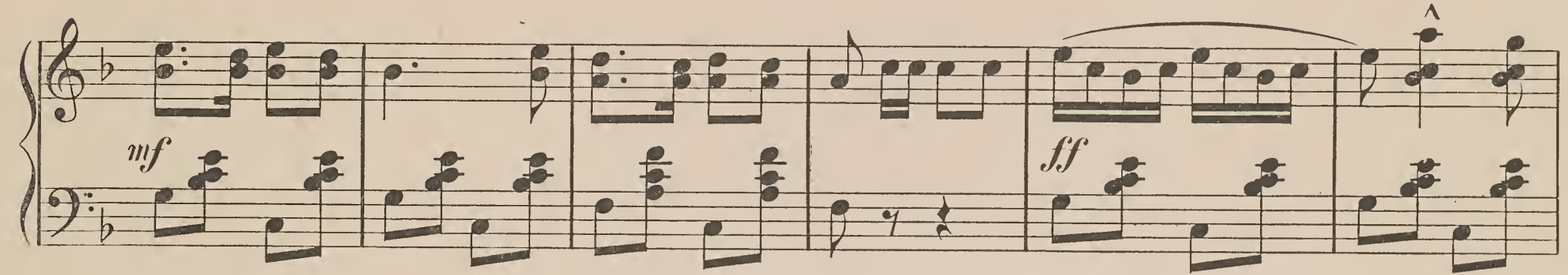

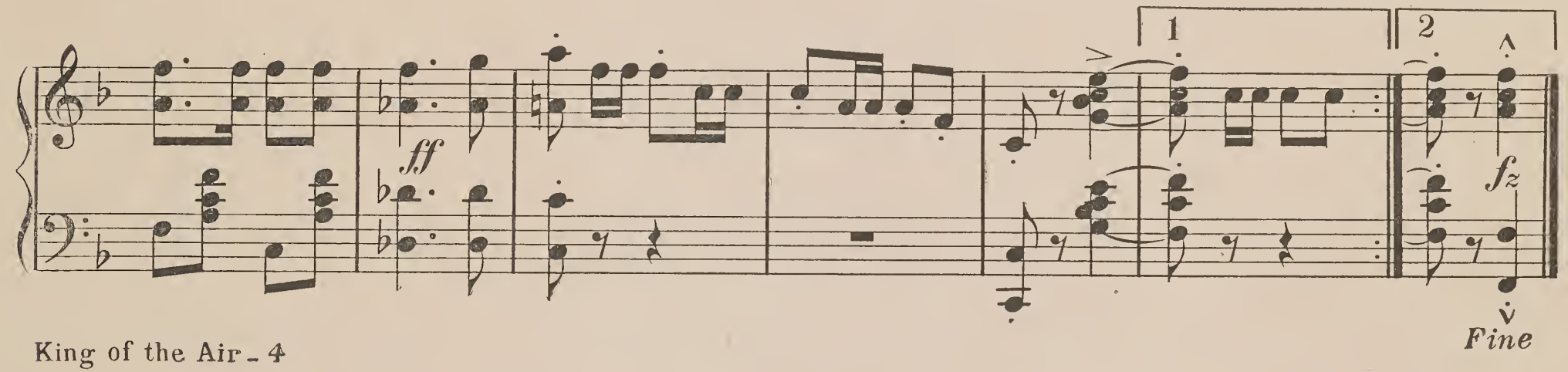


A Trip to Niagara Falls.

策2

Fon

(7)

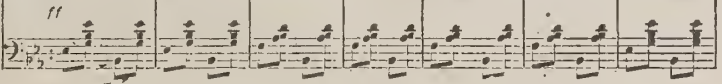

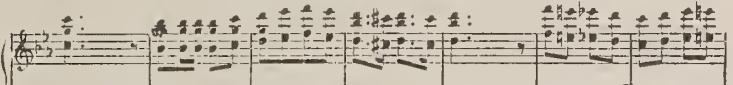

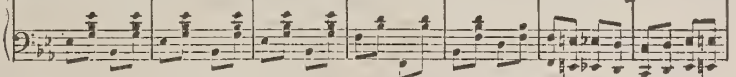

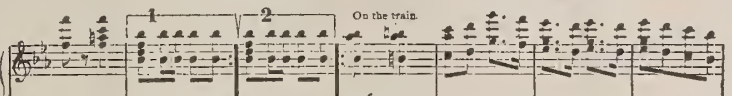

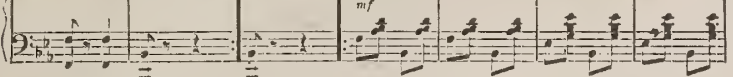

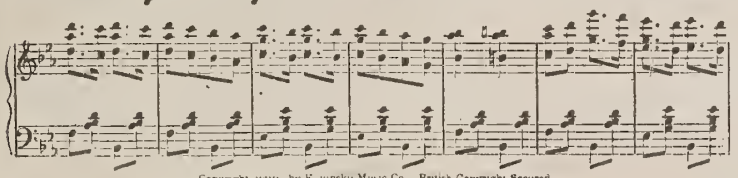

Evening Thoughts

By Kathryn Bayley

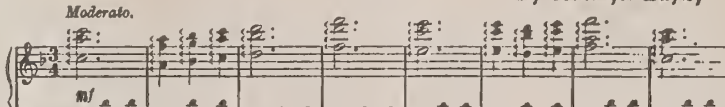

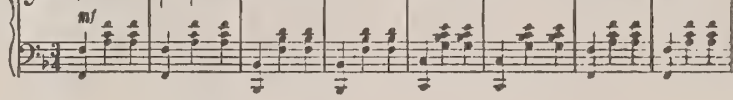

(5):

(俈)

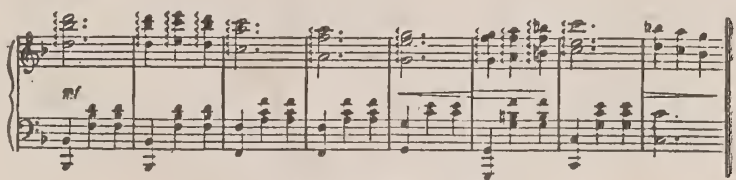

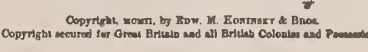

“LOVE'S SERENADE”
LOVE TALES.

WALTZES

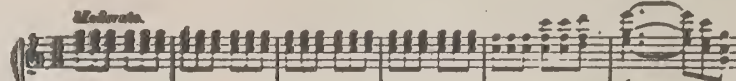

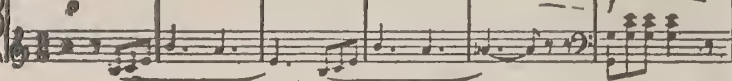
(1)

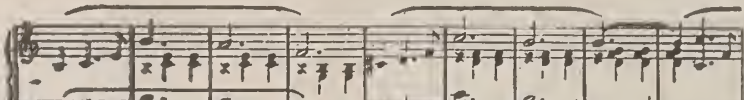
进

(1) 1. . . . . .

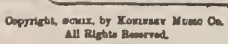

KATHRYN BAYLEY.

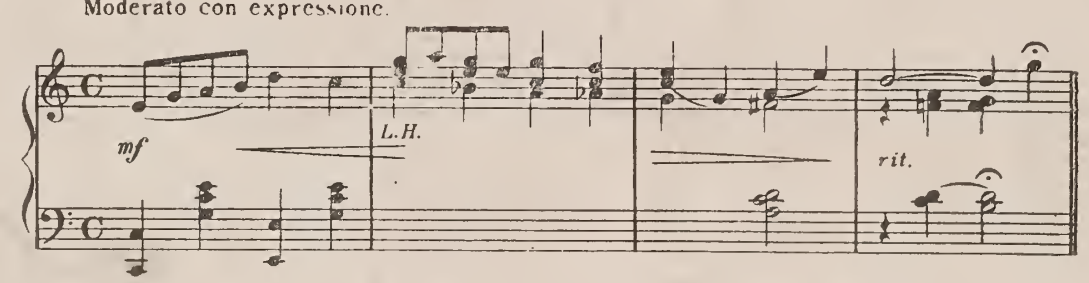

Kathryn

Bayley's

Latest

Success
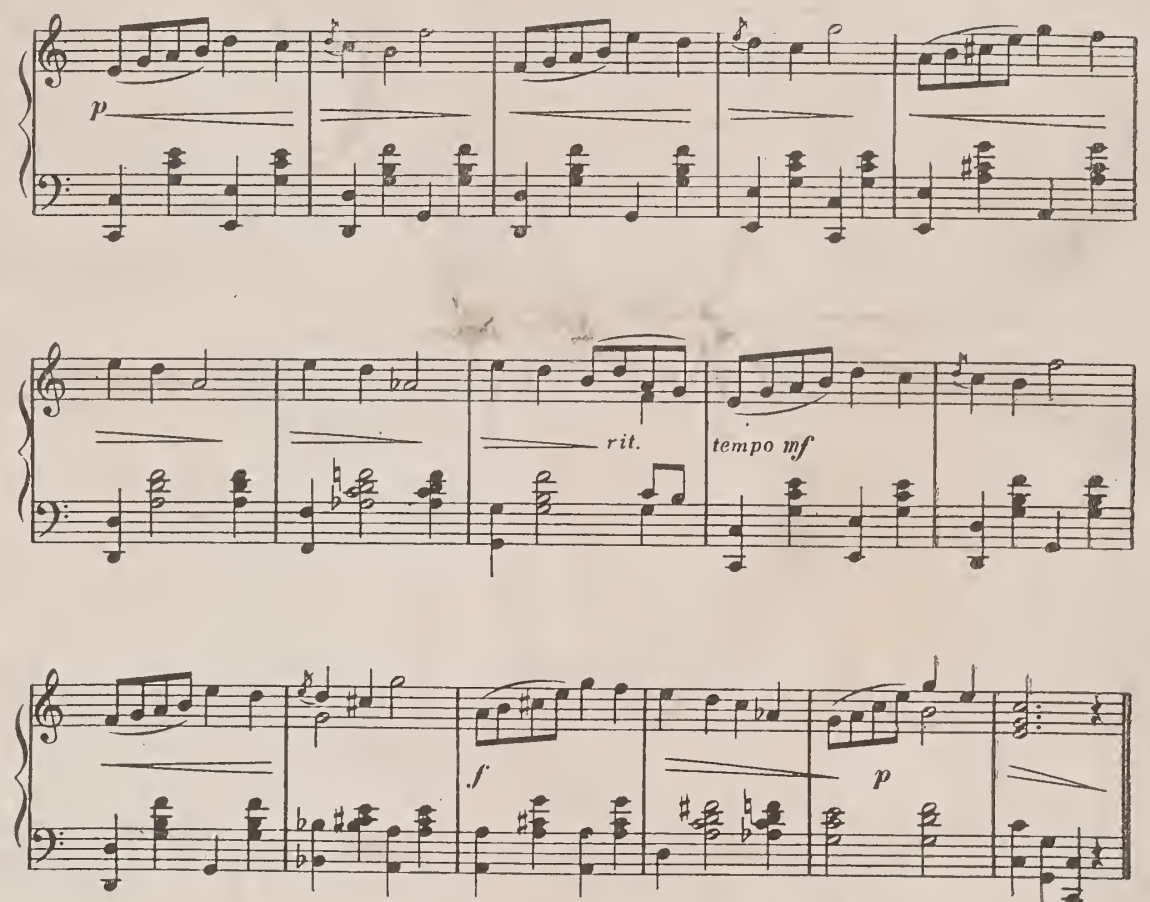

Copyright MCMX by Koninsky Music Co.

UNCLE SAM'S BOYS.

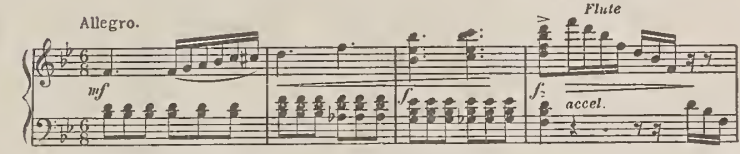

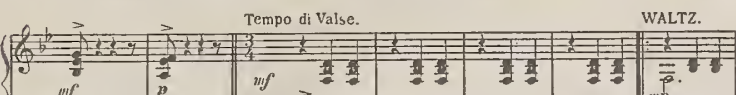

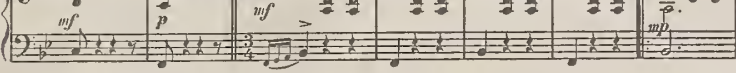

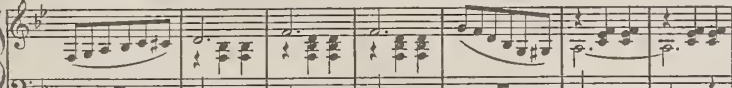

$200+2$

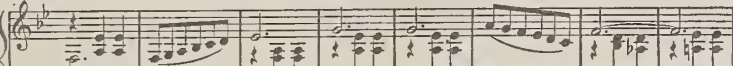

(2)

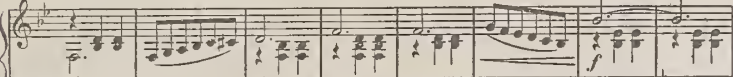

(2) $=0$

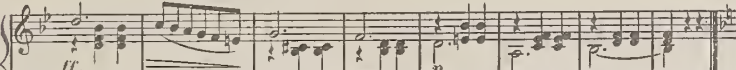

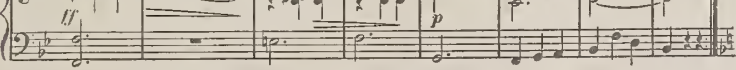

UNCLE SAM'S BOYS.

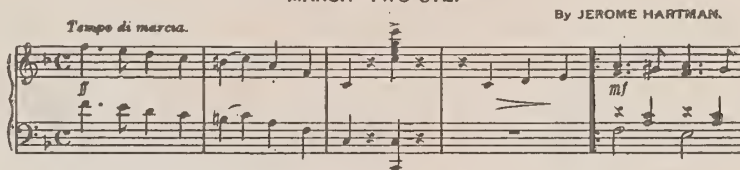

(1)1001401

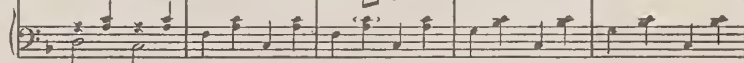

(2) o 2 (1)

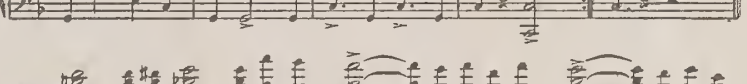

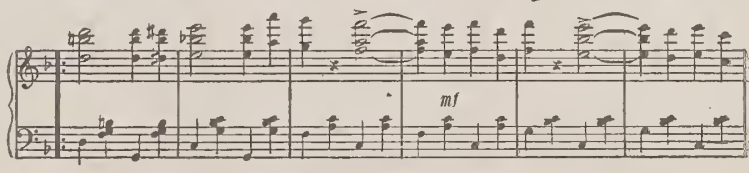

Growing

More

Popular

Every Day
BEALTIFUL QLEEN ()F NIGHT. REVERIE.

Composed by RALPH $\mathrm{K}$ ĖTTCKER 